\title{
Clinical Meaning of the Ratio of Brachial Pre-Ejection Period to Brachial Ejection Time in Patients with Left Ventricular Systolic Dysfunction
}

\author{
Comparison with B-type Natriuretic Peptide
}

Kyoung-Ha Park, ${ }^{1}$ MD, Woo Jung Park, ${ }^{1}$ MD, Sang Jin Han, ${ }^{1}$ MD, Hyun-Sook Kim, ${ }^{1}$ MD, Sang Ho Jo, ${ }^{1}$ MD, Sung-Ai Kim, ${ }^{1}$ MD and Sang Won Suh, ${ }^{2}$ MD

\begin{abstract}
Summary
An increase in the ratio of the brachial pre-ejection period to brachial ejection time [pre-ejection period (PEP)/ET] is correlated with a decrease of left ventricular ejection fraction (LVEF). The current study was designed to test the hypothesis that the change value $(\Delta)$ of PEP/ET is a useful indicator of $\Delta$ LVEF in patients with left ventricular systolic dysfunction.

We consecutively enrolled 104 patients with left ventricular systolic dysfunction (LVEF $<45 \%$ ). PEP/ET, B-type natriuretic peptide (BNP), and LVEF were evaluated at baseline and at 6-month follow-up. Compared with the baseline measurements, the 6-month values of $\triangle \mathrm{LVEF}, \triangle \mathrm{BNP}$, and $\triangle \mathrm{PEP} / \mathrm{ET}$ were $9.8 \% \pm 9.0 \%$ (from $36.3 \% \pm 9.2 \%$ to $46.3 \% \pm 12.5 \%, P<0.001$ ), $-168.5 \pm 255.4$ (from $271.4 \pm 282.5$ to $104.1 \pm 129.6, P<$ 0.001 ), and $-0.060 \pm 0.069$ (from $0.413 \pm 0.097$ to $0.358 \pm 0.079, P<0.001$ ), respectively. There were significant correlations between LVEF and PEP/ET and between LVEF and BNP in both the initial $(r=-0.316, P=$ 0.001 and $r=-0.598, P<0.001$, respectively) and 6-month follow-up $(r=-0.307, P=0.003$ and $r=-0.701, P$ $<0.001$, respectively). The Steiger's $Z$ test showed that BNP had a significantly stronger correlation with LVEF compared with the correlations between LVEF and PEP/ET in both the initial and 6-month studies $(Z=2.471$, $P=0.013$ and $Z=3.575, P<0.001$, respectively). There were also significant correlations between $\triangle \mathrm{LVEF}$ and $\triangle$ PEP/ET $(r=-0.515, P<0.001)$ and between $\triangle$ LVEF and $\triangle \mathrm{BNP}(r=-0.581, P<0.001)$; however, there was no difference between the correlations for $\triangle \mathrm{LVEF}$ and $\triangle \mathrm{PEP} / \mathrm{ET}$ versus $\triangle \mathrm{LVEF}$ and $\Delta \mathrm{BNP}$ (Steiger's $Z=0.600$, $P=0.545)$.

In patients with left ventricular systolic dysfunction not only $\triangle \mathrm{BNP}$ but also $\triangle \mathrm{PEP} / \mathrm{ET}$ could be a simple indicator of predicting change of LVEF.
\end{abstract}

(Int Heart J 2018; 59: 566-572)

Key words: Heart failure, Left ventricular ejection fraction, Ankle-brachial index device

$\mathrm{S}$ tudies have reported that decreased left ventricular systolic function is significantly correlated with an increased risk of future cardiovascular events. ${ }^{1,2}$ Echocardiography is considered the gold standard for evaluation of left ventricular systolic dysfunction; however, limited availability and high cost prohibit it from being used in a general screening and serial follow up. ${ }^{3,4}$ Several studies have analyzed the assessment of B-type natriuretic peptide (BNP) levels for ruling out heart failure, and have raised expectations about left ventricular systolic dysfunction in clinical follow-up. ${ }^{5,6)}$

An ankle-brachial index (ABI)-form device has been developed to measure blood pressure and pulse waves using an automated oscillometric method. This device calcu- lates the brachial pre-ejection period (PEP) and brachial ejection time (ET) by analyzing the signals from the electrocardiogram, phonocardiogram and brachial pressure volume waveform. ${ }^{7)}$ A previous cross-sectional study reported that PEP over ET (PEP/ET) was significantly correlated with left ventricular ejection fraction (LVEF), and this could be a useful parameter in the prediction of left ventricular systolic dysfunction in a single moment. ${ }^{8)}$ However, there has been no study evaluating the relationship between the change value of PEP/ET ( $\triangle \mathrm{PEP} / \mathrm{ET})$ and changes of LVEF ( $\triangle \mathrm{LVEF}$ ) in patients with heart failure. The aim of the present study was to investigate whether $\triangle \mathrm{PEP} / \mathrm{ET}$ is a useful predictor of $\triangle \mathrm{LVEF}$ in patients with newly-diagnosed heart failure.

From the ${ }^{1}$ Division of Cardiovascular Disease, Hallym University Medical Center, Anyang, Korea and ${ }^{2}$ Department of Physiology, College of Medicine, Hallym University, Chuncheon, Korea.

This work was supported by the National Research Foundation of Korea funded by the Ministry of Science, ICT, \& Future Planning (NRF-2017R1D1A3B 03028830) to KH Park.

Address for correspondence: Kyoung-Ha Park, MD, Cardiovascular Division, Department of Internal Medicine, Hallym University Medical Center, 896, Pyeongchon-dong, Dongan-gu, Anyang-si, Gyeonggi-do, Korea. E-mail: pkhmd@naver.com

Received for publication May 30, 2017. Revised and accepted July 25, 2017.

Released in advance online on J-STAGE April 20, 2018.

doi: 10.1536/ihj.17-302

All rights reserved by the International Heart Journal Association. 


\section{Methods}

Patients: All patients in this study were newly diagnosed with heart failure and they had left ventricular systolic dysfunction, defined as impaired LVEF of $\leq 45 \%$, regardless of ischemic and non-ischemic origin, and none of the patients had previously been treated for heart failure. The exclusion criteria included age of $>65$ years, atrial fibrillation, significant valvular heart disease (greater than a moderate degree), complete left bundle branch block, ABI of $<0.9$, inadequate visualization on echocardiography, and inability to follow up. In cases of acute coronary syndrome and acute heart failure, the patients were evaluated in stable condition one or two days before discharge. To evaluate the relationship between the changes in PEP/ET, BNP, and LVEF, all of these measurements were evaluated at baseline and at 6-month follow up. This study was approved by the institutional review board of the Hallym University and all patients gave written informed consent to participate in this study.

Assessment of brachial PEP and ET: The PEP and ET were measured in a quiet, temperature-controlled room with an ABI-form device (Colin VP2000, Komaki, Japan), which automatically and simultaneously measures blood pressure in both arms and ankles using oscillometric method. ${ }^{78)}$ The ET was automatically measured from the foot to the dicrotic notch of the pulse volume waveform. Total electromechanical systolic interval (QS2) was measured from the onset of the QRS complex on the electrocardiogram to the first high-frequency vibration of the aortic component of the second heart sound on the phonocardiogram. The PEP was also automatically calculated by subtracting the ET from the QS2. The values of ABI and brachial-ankle pulse wave velocity (baPWV) were also measured; the measurement method is reported and validated in previous studies. ${ }^{7-9)}$

Echocardiographic assessment: Comprehensive echocardiographic images were obtained using a commercially available Vivid 7 machine (GE Medical Systems, Milwaukee, WI, USA) echocardiographic system. Echocardiography was performed according to the guidelines of the American Society of Echocardiography recommendations. ${ }^{10)}$ Mitral flow recorded with pulsed Doppler was placed between the tips of the mitral valves. The ratio between early (E) and late (A) mitral inflow was calculated (E/A), and the E-wave deceleration time was measured. Tissue spectral Doppler recordings were performed in the septal annular plane. The early diastolic medial mitral annular velocity (E') was measured and the E/E' ratio was calculated for the septal wall. Measurements were made online, recorded digitally, and interpreted off-line by echocardiography physicians blinded to the clinical data. The LVEF was quantified by the modified Simpson's rule using two-dimensional echocardiography images from the apical four- and two-chamber views.

Measurements of plasma BNP: Plasma BNP levels were measured directly with validated and commercially available immunoassay kits (Architect BNP, Abbott Laboratories, IL, USA).

Statistical analysis: Statistical analysis was performed using SPSS 22.0 (SPSS, Inc., Chicago, IL, USA). Data are expressed as percentages or as mean \pm standard deviation. Comparisons between index and follow-up measures were tested with the paired $t$-test or Wilcoxon's signed rank test, as appropriate. Correlations between variables were evaluated with Spearman's rank correlation. The differences between correlations involving a common variable were tested using Steiger's $Z$ test to account for the dependency of the correlations. To determine whether there is an additional advantage to using the combined parameter $\triangle \mathrm{PEP} / \mathrm{ET}$ plus $\triangle \mathrm{BNP}(\triangle \mathrm{PEP} / \mathrm{ET} \& \mathrm{BNP})$ over $\triangle \mathrm{BNP}$ in predicting $\triangle \mathrm{LVEF}, \triangle \mathrm{PEP} / \mathrm{ET} \& \mathrm{BNP}$ was formulated as $\triangle \mathrm{BNP}$ added to $\triangle \mathrm{PEP} / \mathrm{ET}^{*} 1000$. The $\mathrm{PEP} / \mathrm{ET}^{*} 1000$ was used to tune in the number of digits between BNP and PEP/ET. The multivariable linear regression analysis was evaluated with the associated variables to assess independent correlates of the $\triangle \mathrm{LVEF}$. All statistical tests were twosided, and a $P$-value of $<0.05$ was considered statistically significant.

\section{Results}

We consecutively screened 120 patients with LVEF $\leq$ $45 \%$ between January 2014 and May 2015. Sixteen of these patients were excluded due to atrial fibrillation $(n=$ $3)$, ABI $<0.9(n=2)$, significant valvular heart disease $(n$ $=4)$, complete left bundle branch block $(n=2)$, inadequate echocardiographic imaging $(n=1)$, or refusal to participate in the study $(n=4)$. A total of 104 patients were included in the final analysis. During the study period nine patients $(8.7 \%)$ were lost to follow-up, meaning a total of 95 patients finished the study. In this study, 82 of 104 patients had ischemic heart failure. Among them, 73 patients had acute myocardial infarction and all of them underwent emergency percutaneous coronary intervention (PCI). Nine patients had chronic ischemic heart failure due to multi-vessel disease. Five patients had undergone PCI, two had undergone coronary artery bypass graft $(\mathrm{CABG})$ operation, and two were treated with only medical therapy because they refused PCI or CABG. The baseline clinical characteristics are shown in Table I.

The results of the initial and 6-month follow-up findings of echocardiographic, BNP, and ABI data are described in Table II. The $\triangle \mathrm{PEP}$ was $-0.9 \pm 14.5$ and $\triangle \mathrm{ET}$ was $40.0 \pm 33.1$. The values of $\triangle \mathrm{LVEF}, \triangle \mathrm{BNP}$, and $\triangle \mathrm{PEP} /$ ET were $9.8 \% \pm 9.0 \%,-168.5 \pm 255.4$, and $-0.060 \pm$ 0.069 , respectively. Table III shows the correlations between LVEF, PEP/ET and BNP. In both the initial and 6month follow-up studies, there were significant correlations between LVEF and PEP/ET and between LVEF and BNP. In both the initial and 6-month evaluations, however, Steiger's $Z$ test showed that BNP had a significantly stronger correlation with LVEF compared with the correlations between LVEF and PEP/ET. There was a significant correlation between $\triangle \mathrm{LVEF}$ and $\triangle \mathrm{PEP} / \mathrm{ET}(r=-$ $0.515, P<0.001$; Figure $1 \mathrm{~A}$ ), which was stronger than the correlation between $\triangle \mathrm{LVEF}$ and $\triangle \mathrm{PEP}(r=-0.320, P$ $=0.002)$ and between $\triangle \mathrm{LVEF}$ and $\triangle \mathrm{ET}(r=0.310, P=$ $0.002)$. There was also a significant correlation between $\triangle \mathrm{LVEF}$ and $\triangle \mathrm{BNP}(r=-0.581, P<0.001)$ (Figure $1 \mathrm{~B})$. However, there was no difference in the correlations between $\triangle \mathrm{LVEF}$ and $\triangle \mathrm{PEP} / \mathrm{ET}$ versus $\triangle \mathrm{LVEF}$ and $\triangle \mathrm{BNP}(r$ 
Table I. Baseline Clinical Characteristics

\begin{tabular}{|c|c|c|c|c|}
\hline Variable & Value $(n=104)$ & Initial $(n=104)$ & 6-month $(n=95)$ & $P$ \\
\hline Age, years & $58 \pm 9$ & & & \\
\hline Male, $n(\%)$ & $82(78.8)$ & & & \\
\hline History of smoking, $n(\%)$ & $56(53.8)$ & & & \\
\hline Hypertension, $n(\%)$ & $48(46.2)$ & & & \\
\hline Dyslipidemia, $n(\%)$ & $53(51.0)$ & & & \\
\hline Diabetes, $n(\%)$ & $34(32.7)$ & & & \\
\hline Family history of CHD, $n(\%)$ & $10(9.6)$ & & & \\
\hline Body mass index, $\mathrm{kg} / \mathrm{m}^{2}$ & $24.4 \pm 3.1$ & & & \\
\hline Systolic blood pressure, $\mathrm{mmHg}$ & $122 \pm 22$ & & & \\
\hline Diastolic blood pressure, $\mathrm{mmHg}$ & $74 \pm 11$ & & & \\
\hline Heart rate, beats/minute & $78 \pm 10$ & & & \\
\hline Ischemic heart failure, $n(\%)$ & $82(78.8)$ & & & \\
\hline Acute myocadial infarction & $73(70.2)$ & & & \\
\hline Chronic multi-vessel disease & $9(8.6)$ & & & \\
\hline Non-ischemic heart failure, $n(\%)$ & $22(21.2)$ & & & \\
\hline \multicolumn{5}{|l|}{ Laboratory data } \\
\hline Hemoglobin (mg/dL) & $14.4 \pm 1.5$ & & & \\
\hline Fasting blood sugar $(\mathrm{mg} / \mathrm{dL})$ & $118 \pm 41$ & & & \\
\hline Creatinine $(\mathrm{mg} / \mathrm{dL})$ & $0.8 \pm 0.3$ & & & \\
\hline Total cholesterol (mg/dL) & $200 \pm 38$ & & & \\
\hline Triglyceride $(\mathrm{mg} / \mathrm{dL})$ & $141 \pm 70$ & & & \\
\hline $\mathrm{HDL}-\mathrm{C}(\mathrm{mg} / \mathrm{dL})$ & $45 \pm 11$ & & & \\
\hline LDL-C (mg/dL) & $119 \pm 37$ & & & \\
\hline \multicolumn{5}{|l|}{ Medication } \\
\hline Aspirin, $n(\%)$ & & $85(81.7)$ & $77(81.0)$ & 1.000 \\
\hline Statin, $n(\%)$ & & $88(84.6)$ & $78(82.1)$ & 0.500 \\
\hline ACE-inhibitor, $n(\%)$ & & $69(66.3)$ & $62(65.3)$ & 1.000 \\
\hline Beta-blocker, $n(\%)$ & & $95(91.3)$ & $84(88.4)$ & 0.453 \\
\hline Nitrate, $n(\%)$ & & $49(47.1)$ & $40(42.1)$ & 0.289 \\
\hline Loop diuretics, $n(\%)$ & & $47(45.2)$ & $39(41.0)$ & 0.219 \\
\hline Aldosterone, $n(\%)$ & & $42(40.4)$ & $38(40.0)$ & 0.625 \\
\hline Digoxin, $n(\%)$ & & $10(9.6)$ & $8(8.4)$ & 1.000 \\
\hline
\end{tabular}

ACE indicates angiotensin converting enzyme; CHD, coronary heart disease; HDL-C, high density lipoprotein cholesterol; and LDL-C, low density lipoprotein cholesterol.

$=-0.515, P<0.001$ versus $r=-0.581, P<0.001$; Steiger's $Z=0.600, P=0.545)$. There was a significant correlation between $\triangle \mathrm{LVEF}$ and $\triangle \mathrm{PEP} / \mathrm{ET} \& \mathrm{BNP}(r=-0630$, $P<0.001$; Figure 2). However, the combined parameters of $\triangle \mathrm{PEP} / \mathrm{ET} \& \mathrm{BNP}$ did not show a stronger correlation with $\triangle \mathrm{LVEF}$ compared with $\triangle \mathrm{BNP}$ alone $(r=-0.630, P<$ 0.001 versus $r=-0.581, P<0.001$; Steiger's $Z=0.496, P$ $=0.620)$. In patients with non-ischemic heart failure $(n=$ 22), $\triangle \mathrm{PEP} / \mathrm{ET} \& \mathrm{BNP}$ was more strongly correlated with $\triangle \mathrm{LVEF}$ than it was in the 82 patients with ischemic heart failure $(r=-0.765$ versus $r=-0.524$, all $P<0.001)$.

In this study, compared with the initial study, there were significant changes in heart rate (HR), systolic blood pressure, and diastolic blood pressure, and the $\Delta \mathrm{HR}$, $\triangle \mathrm{SBP}$, and $\triangle \mathrm{DBP}$ values were $-13.2 \pm 11.1 /$ minute, $3.8 \pm$ $21.1 \mathrm{mmHg}$, and $2.8 \pm 12.3 \mathrm{mmHg}$, respectively (Table II). In addition, PEP and ET may be affected by changes in heart rate and blood pressure. ${ }^{8,11)}$ Therefore, the multivariable linear regression analysis was evaluated to assess independent correlates of the $\triangle \mathrm{LVEF}$, including $\triangle \mathrm{HR}$, $\triangle \mathrm{SBP}, \triangle \mathrm{DBP}, \triangle \mathrm{BNP}$, and $\triangle \mathrm{PEP} / \mathrm{ET}$. The analysis showed that the $\triangle \mathrm{BNP}$ and $\triangle \mathrm{PEP} / \mathrm{ET}$ were independently correlated with $\triangle$ LVEF (Table IV).

\section{Discussion}

The present study demonstrated that $\triangle \mathrm{PEP} / \mathrm{ET}$ could be a simple indicator of predicting $\triangle \mathrm{LVEF}$ in patients with decreased LVEF, and this is similar to the relationship between $\triangle \mathrm{BNP}$ and $\triangle \mathrm{LVEF}$. To the best of our knowledge, this is the first report to demonstrate a significant correlation between $\triangle \mathrm{PEP} / \mathrm{ET}$ from the ABI-form device and $\triangle \mathrm{LVEF}$.

Decreased left ventricular systolic function was reported to predict poor CV outcomes. ${ }^{1,2)}$ Therefore, assessment of changes in left ventricular function treated after medical or revascularization procedures is an important clinical issue in patients with left ventricular systolic dysfunction. ${ }^{12)}$ In this study, most echocardiographic parameters, including LVEF, as well as HR and BNP, were improved because most patients who had ischemic heart failure underwent reperfusion therapy and all patients were treated with optimal medical therapy.

BaPWV-derived PEP/ET automatically obtained from an ABI-form device may be helpful in estimating left ventricular systolic function. The prolongation of PEP could be caused by a diminished rate of left ventricular pressure rise during isovolumic contraction. ${ }^{13)}$ Therefore, when left ventricular systolic function decreases, the PEP value will 
Table II. Results of Initial and 6-month Follow-up Echocardiography, BNP, and ABI

\begin{tabular}{lccr}
\hline & Initial $(n=104)$ & 6 -month $(n=95)$ & \multicolumn{1}{c}{$P$} \\
\hline LVEF $(\%)$ & $36.3 \pm 9.2$ & $46.3 \pm 12.5$ & $<0.001$ \\
LVMI $\left(\mathrm{g} / \mathrm{m}^{2}\right)$ & $100.0 \pm 30.3$ & $97.1 \pm 23.3$ & 0.112 \\
LVEDd $(\mathrm{mm})$ & $51.1 \pm 7.0$ & $49.5 \pm 7.0$ & 0.096 \\
LVESd $(\mathrm{mm})$ & $39.0 \pm 8.9$ & $37.7 \pm 9.1$ & 0.148 \\
E velocity $(\mathrm{cm} / \mathrm{s})$ & $73.3 \pm 15.9$ & $66.4 \pm 16.4$ & 0.006 \\
A velocity $(\mathrm{cm} / \mathrm{s})$ & $67.8 \pm 17.3$ & $70.1 \pm 16.2$ & 0.248 \\
DT $(\mathrm{ms})$ & $185.3 \pm 41.1$ & $220.6 \pm 44.8$ & $<0.001$ \\
E/A & $1.3 \pm 1.1$ & $1.0 \pm 0.4$ & 0.005 \\
E' velocity (cm/s) & $5.9 \pm 1.7$ & $6.3 \pm 1.7$ & 0.006 \\
E/E' & $13.4 \pm 4.5$ & $11.4 \pm 4.4$ & $<0.001$ \\
BNP, pg/mL & $271.4 \pm 282.5$ & $104.1 \pm 129.6$ & $<0.001$ \\
Systolic blood pressure, mmHg & $122 \pm 22$ & $125 \pm 16$ & 0.002 \\
Diastolic blood pressure, mmHg & $74 \pm 11$ & $77 \pm 10$ & 0.030 \\
Heart rate, beats/minute & $77 \pm 9$ & $64 \pm 10$ & $<0.001$ \\
Left ABI & $1.14 \pm 0.09$ & $1.14 \pm 0.08$ & 0.535 \\
baPWV & $1558 \pm 329$ & $1504 \pm 333$ & 0.015 \\
PEP & $103.0 \pm 18.5$ & $102.9 \pm 15.3$ & 0.540 \\
ET & $254.1 \pm 31.1$ & $292.5 \pm 29.3$ & $<0.001$ \\
PEP/ET & $0.413 \pm 0.097$ & $0.358 \pm 0.079$ & $<0.001$ \\
\hline ABI indicates ankle brachis
\end{tabular}

ABI indicates ankle brachial index; A velocity, late diastolic mitral inflow velocity; baPWV, brachial-ankle pulse wave velocity; BNP, b-type natriuretic peptide; DT, deceleration time; E/E', ratio of early diastolic mitral inflow velocity (E) and early diastolic medial mitral annular velocity (E'); ET, ejection time; LVEF, left ventricular ejection fraction; LVEDd, left ventricular end-diastolic diameter; LVESd, left ventricular endsystolic diameter; LVMI, left ventricular mass index; and PEP, pre-ejection period.

Table III. Correlation between LVEF and Variables of $\mathrm{PEP} / \mathrm{ET}$ and BNP

\begin{tabular}{lrrr}
\hline & $r$ & $P$ & Steiger's $Z$ \\
\hline Initial & & & \\
LVEF and PEP/ET & -0.316 & 0.001 & $Z=2.471$ \\
LVEF and BNP & -0.598 & $<0.001$ & $P=0.013$ \\
Six-month follow-up & & & \\
LVEF and PEP/ET & -0.307 & 0.003 & $Z=3.575$ \\
LVEF and BNP & -0.701 & $<0.001$ & $P<0.001$ \\
\hline
\end{tabular}

All $r$ values are from Spearman's correlation. BNP indicates b-type natriuretic peptide; ET, ejection time; LVEF, left ventricular ejection fraction; and PEP, pre-ejection period.

increase. ${ }^{14)}$ The duration of ET reflects both the velocity and extent of fiber shortening of the left ventricle. In left ventricular decompensation, the extent of fiber shortening is decreased and the ET will be shortened. ${ }^{15)}$ Because heart function impairment usually prolongs PEP and shortens ET, the PEP/ET value may reflect the diagnostic value of the identification of left ventricular systolic dysfunction. Until now, studies have reported that the ratio of $\mathrm{PEP} / \mathrm{ET}$ is well correlated with left ventricular systolic dysfunction in patients with and without various forms of cardiovascular disease. ${ }^{14-16)}$ This also implies that patients with increased PEP/ET might be in a high risk group for increased $\mathrm{CV}$ events in the presence of chronic kidney disease. ${ }^{17)}$ Both PEP and ET correlated significantly with LVEF, which was consistent with the findings in our study. ${ }^{15)}$ However, the correlation relating $\triangle \mathrm{PEP}$ and $\triangle \mathrm{ET}$ with changes in LVEF was less than that for $\triangle \mathrm{PEP} / \mathrm{ET}$ and changes in LVEF in this study. Hence, compared with $\triangle \mathrm{PEP}$ and $\triangle \mathrm{ET}, \triangle \mathrm{PEP} / \mathrm{ET}$ might be a useful predictor of $\triangle \mathrm{LVEF}$ in patients with left ventricular systolic dysfunction. Similarly, the initial and 6-month values of PEP/ET were weakly correlated with LVEF compared with $\triangle \mathrm{PEP} /$ ET and $\triangle$ LVEF. In other words, serial changes in PEP/ET are more valuable for predicting left ventricular systolic function than one point values of PEP/ET. This is similar to the relationship between $\mathrm{BNP}$ and C-reactive protein. $^{18,19)}$ More clinical information can generally be obtained when serial changes of measured data are available, compared with one point values.

The value of assessment of BNP levels for the diagnosis of heart failure or left ventricular dysfunction has been widely accepted, and BNP has been recommend for ruling out heart failure. ${ }^{6,20)}$ However, not only single moment BNP values but also changes in BNP over time have clinical significance. ${ }^{18,21)}$ Therefore, several studies have evaluated the correlations between $\triangle \mathrm{BNP}, \triangle \mathrm{LVEF}$, and cardiovascular outcomes, and a significant correlation between $\triangle \mathrm{BNP}$ and recovery of LV systolic function after coronary bypass surgery has been reported. ${ }^{12)}$ In patients with mitral regurgitation, there was a significant negative association between changes in LVEF and $\triangle \mathrm{BNP}$ after mitral annuloplasty. ${ }^{22)}$ In the J-CHF study, $\triangle \mathrm{BNP}$ was a predictor of long-term cardiovascular outcomes after carvedilol treatment. ${ }^{23)}$ The Valsartan Heart Failure Therapy Trial showed that the relative change in BNP strongly predicted outcomes and superseded the prognostic value of a single BNP measurement. ${ }^{24)}$ In the present study, both the initial and 6-month values of BNP had a stronger correlation with LVEF compared with those between ET/PEP and LVEF. However, the value of $\triangle \mathrm{PEP} / \mathrm{ET}$ had a strong correlation with $\triangle \mathrm{LVEF}$, and there was no difference between $\triangle \mathrm{PEP} / \mathrm{ET}$ with $\triangle \mathrm{LVEF}$ versus $\triangle \mathrm{BNP}$ with $\triangle \mathrm{LVEF}$ 

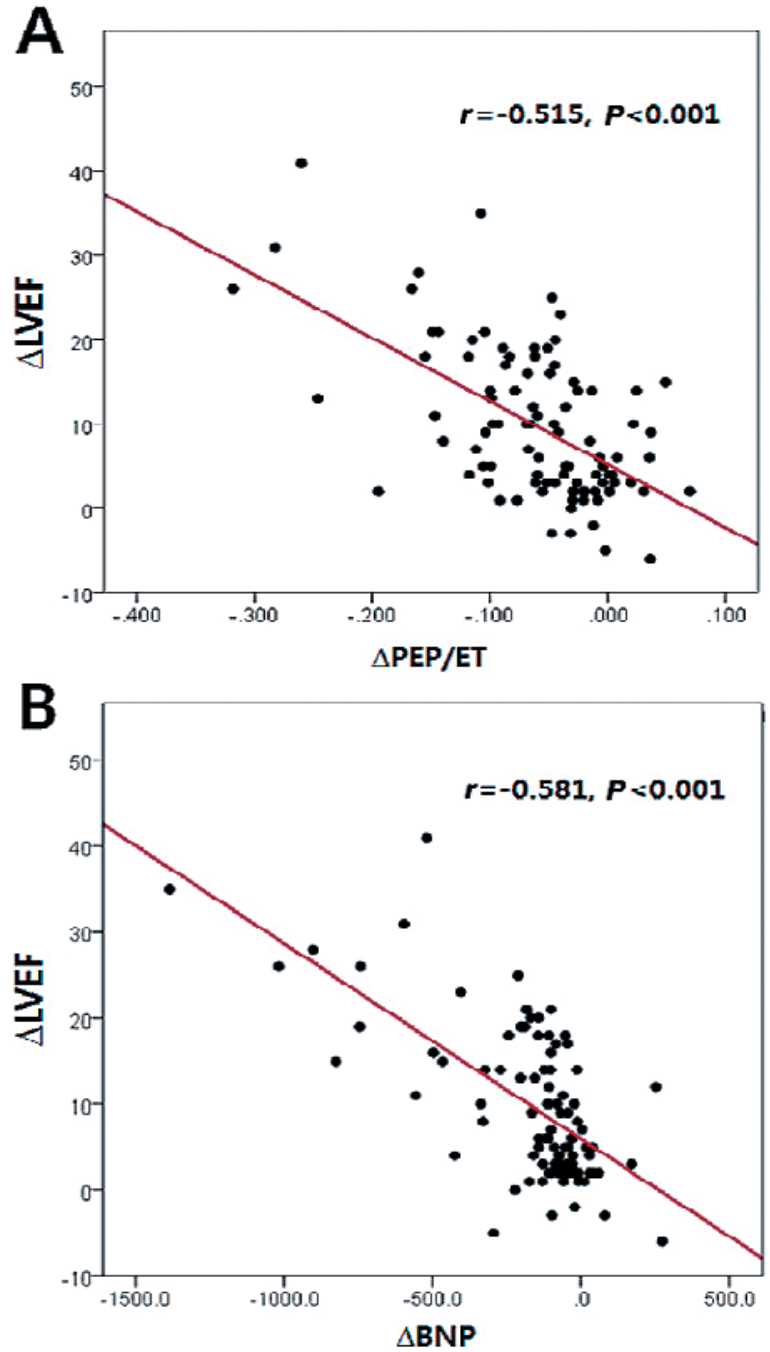

Figure 1. Interrelationships between change in left ventricular ejection fraction and change in PEP/ET (A), and between change in left ventricular ejection fraction and change in BNP $(\mathbf{B})$. All values are from Spearman's correlation. $\triangle \mathrm{BNP}$, change in B-type natriuretic peptide; $\triangle \mathrm{PEP} / \mathrm{ET}$, change in pre-ejection period/ change in ejection time; $\triangle \mathrm{LVEF}$, change in left ventricular ejection fraction

( $r=-0.515$ versus $r=-0.581$; Steiger's $Z=0.600, P=$ $0.545)$. In addition, the combined parameter of $\triangle \mathrm{PEP} /$ ET\&BNP was not more strongly correlated with $\triangle \mathrm{LVEF}$ versus $\triangle \mathrm{BNP}$ alone $(r=-0.630$ versus $r=-0.581$; Steiger's $Z=0.496, P=0.620$ ). This indicates that there was no additive value of $\triangle \mathrm{PEP} / \mathrm{ET} \& \mathrm{BNP}$ over $\triangle \mathrm{BNP}$ in predicting $\triangle \mathrm{LVEF}$; however, considered differently, this also means that there was no difference between $\triangle \mathrm{PEP} / \mathrm{ET}$ and $\triangle \mathrm{BNP}$ in predicting changes in left ventricular systolic function.

This study included $82(79 \%)$ patients with ischemic and $22(21 \%)$ patients with non-ischemic left ventricular dysfunction. In patients with non-ischemic heart failure, $\triangle \mathrm{PEP} / \mathrm{ET} \& \mathrm{BNP}$ was more strongly correlated with $\triangle \mathrm{LVEF}$ than in the patients with ischemic heart failure $(r$ $=-0.765$ versus $r=-0.524)$. The 6-month follow-up BNP measurement showed a strong correlation with LVEF

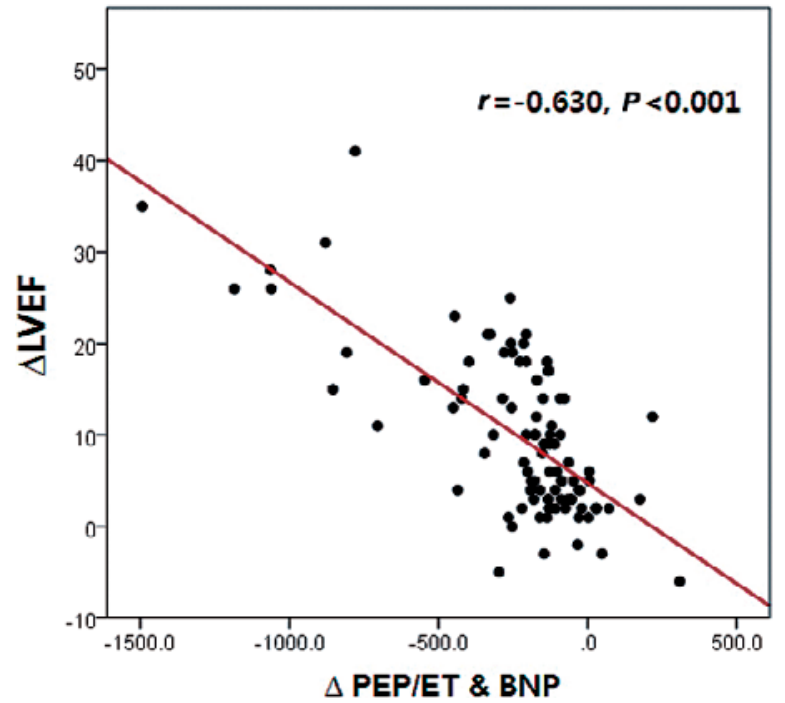

Figure 2. Correlation between change in LVEF and change in PEP/ ET\&BNP. The value is from Spearman's correlation. $\triangle P E P / E T \& B N P$, change in pre-ejection period/ change in ejection time*1000 plus change in B-type natriuretic peptide; $\triangle \mathrm{LVEF}$, change in left ventricular ejection fraction

compared with that between initial BNP and LVEF ( $r=$ -0.701 versus $r=-0.598$ ). This may be because, in patients with acute myocardial infarction, BNP is less effective in predicting left ventricular systolic function than in patients with non-ischemic heart failure. Generally, the measurement of $\triangle \mathrm{PEP} / \mathrm{ET}$ from $\mathrm{ABI}$ device is more simple and less expensive than get $\triangle \mathrm{LVEF}$ from echocardiography. This leaves not only $\triangle \mathrm{BNP}$ but also $\triangle \mathrm{PEP} / \mathrm{ET}$ as another simple method of predicting changes of left ventricular systolic function after treating patients with decreased LVEF.

Limitations: This study had several potential limitations. First, the subjects were enrolled from only one regional hospital and the number of patients was relatively small. Second, we excluded patents with atrial fibrillation and left bundle branch block because measurements of PEP and ET can be affected by beat-to-beat variation or delayed closure of aortic valve. Third, most of the patients $(82 \%)$ had decreased LVEF due to ischemic heart failure. Fourth, it remains unclear whether the results could be confirmed in a larger patient sample over a longer period. Therefore, further studies with larger numbers of patients and long-term follow up are needed to generalize this observation.

\section{Conclusion}

Our study demonstrated that in patients with left ventricular systolic dysfunction, the serial measurement of $\triangle \mathrm{PEP} / \mathrm{ET}$ is a useful indicator of changes in LVEF and this is similar to the relationship between $\triangle \mathrm{BNP}$ and $\triangle \mathrm{LVEF}$. 
Table IV. Results of the Multivariable Linear Regression to Assess the Independent Correlates of the Delta Left Ventricular Ejection Fraction

\begin{tabular}{lccccc}
\hline & $\begin{array}{c}\text { Unstandardized } \\
\text { coefficient } \beta\end{array}$ & $95 \%$ CI for $\beta$ & $\begin{array}{c}\text { Standardized } \\
\text { coefficient } \beta\end{array}$ & $P$ & VIF \\
\hline$\Delta$ HR & 0.068 & $-0.057,0.193$ & 0.085 & 0.279 & 1.204 \\
$\Delta$ SBP & -0.031 & $-0.125,0.063$ & -0.073 & 0.512 & 2.455 \\
$\Delta$ DBP & 0.058 & $-0.110,0.225$ & 0.079 & 0.496 & 2.667 \\
$\Delta$ BNP & -0.018 & $-0.023,-0.012$ & -0.506 & $<0.001$ & 1.248 \\
$\Delta$ PEP/ET & -53.862 & $-74.678,-33.047$ & -0.416 & $<0.001$ & 1.307 \\
\hline
\end{tabular}

BNP indicates b-type natriuretic peptide; CI, confidence interval; DBP, diastolic blood pressure; ET, ejection time; HR, heart rate; LVEF, left ventricular ejection fraction; PEP, pre-ejection period; SBP, systolic blood pressure; VIF, variance inflation factor; and $\Delta$, delta value of Model $\mathrm{F}$ ratio $=22.048, P<0.001$

\section{Acknowledgments}

The authors thank Mi Jeong Kum, RN, RDCS, and Ock Ki Kim, RDCS, for their invaluable time and effort in performing the serial echocardiography.

\section{Disclosures}

Conflicts of interest: The Authors declare that there is no conflict of interest.

\section{References}

1. Cintron G, Johnson G, Francis G, Cobb F, Cohn JN. Prognostic significance of serial changes in left ventricular ejection fraction in patients with congestive heart failure. The V-HeFT VA Cooperative Studies Group. Circulation 1993; 87: VI17-23.

2. Quinones MA, Greenberg BH, Kopelen HA, et al. Echocardiographic predictors of clinical outcome in patients with left ventricular dysfunction enrolled in the SOLVD registry and trials: significance of left ventricular hypertrophy. Studies of Left Ventricular Dysfunction. J Am Coll Cardiol 2000; 35: 1237-44.

3. Nielsen OW, McDonagh TA, Robb SD, Dargie HJ. Retrospective analysis of the cost-effectiveness of using plasma brain natriuretic peptide in screening for left ventricular systolic dysfunction in the general population. J Am Coll Cardiol 2003; 41: 113-20.

4. Sim V, Hampton D, Phillips C, et al. The use of brain natriuretic peptide as a screening test for left ventricular systolic dysfunction- cost-effectiveness in relation to open access echocardiography. Fam Pract 2003; 20: 570-4.

5. Latour-Perez J, Coves-Orts FJ, Abad-Terrado C, Abraira V, Zamora J. Accuracy of B-type natriuretic peptide levels in the diagnosis of left ventricular dysfunction and heart failure: a systematic review. Eur J Heart Fail 2006; 8: 390-9.

6. Doust JA, Glasziou PP, Pietrzak E, Dobson AJ. A systematic review of the diagnostic accuracy of natriuretic peptides for heart failure. Arch Intern Med 2004; 164: 1978-84.

7. Yamashina A, Tomiyama H, Takeda K, et al. Validity, reproducibility, and clinical significance of noninvasive brachial-ankle pulse wave velocity measurement. Hypertens Res 2002; 25 359-64.

8. Su HM, Lin TH, Lee CS, et al. Myocardial performance index derived from brachial-ankle pulse wave velocity: a novel and feasible parameter in evaluation of cardiac performance. Am J Hypertens 2009; 22: 871-6.

9. Munakata M, Ito N, Nunokawa T, Yoshinaga K. Utility of automated brachial ankle pulse wave velocity measurements in hypertensive patients. Am J Hypertens 2003; 16: 653-7.
10. Lang RM, Bierig M, Devereux RB, et al. Recommendations for chamber quantification: a report from the American Society of Echocardiography's Guidelines and Standards Committee and the Chamber Quantification Writing Group, developed in conjunction with the European Association of Echocardiography, a branch of the European Society of Cardiology. J Am Soc Echocardiogr 2005; 18: 1440-63.

11. Cokkinos DV, Heimonas ET, Demopoulos JN, Harralambakis A, Tsartsalis G, Gardikas CD. Influence of heart rate increase on uncorrected pre-ejection period/left ventricular ejection time (PEP/LVET) ratio in normal individuals. Br Heart J 1976; 38: 683-8.

12. Chello M, Mastroroberto P, Perticone F, et al. Plasma levels of atrial and brain natriuretic peptides as indicators of recovery of left ventricular systolic function after coronary artery bypass. Eur J Cardiothorac Surg 2001; 20: 140-6.

13. Lewis RP, Rittogers SE, Froester WF, Boudoulas H. A critical review of the systolic time intervals. Circulation 1977; 56: 14658.

14. Veyrat C, Larrazet F, Pellerin D. Renewed interest in preejectional isovolumic phase: new applications of tissue Doppler indexes: implications to ventricular dyssynchrony. Am J Cardiol 2005; 96: 1022-30.

15. Garrard CL Jr, Weissler AM, Dodge HT. The relationship of alterations in systolic time intervals to ejection fraction in patients with cardiac disease. Circulation 1970; 42: 455-62.

16. Pellerin D, Cohen L, Larrazet F, Pajany F, Witchitz S, Veyrat C. Preejectional left ventricular wall motion in normal subjects using Doppler tissue imaging and correlation with ejection fraction. Am J Cardiol 1997; 80: 601-7.

17. Chen SC, Chang JM, Tsai JC, et al. A systolic parameter defined as the ratio of brachial pre-ejection period to brachial ejection time predicts cardiovascular events in patients with chronic kidney disease. Circ J 2010; 74: 2206-10.

18. Januzzi JL, Troughton R. Are serial BNP measurements useful in heart failure management? Serial natriuretic peptide measurements are useful in heart failure management. Circulation 2013; 127: 500-7; discussion 8

19. Manian FA. A prospective study of daily measurement of Creactive protein in serum of adults with neutropenia. Clin Infect Dis 1995; 21: 114-21.

20. Remme WJ, Swedberg K. Comprehensive guidelines for the diagnosis and treatment of chronic heart failure. Task force for the diagnosis and treatment of chronic heart failure of the European Society of Cardiology. Eur J Heart Fail 2002; 4: 11-22.

21. Nitta D, Kinugawa K, Imamura T, Kato NP, Komuro I. High dose beta-blocker therapy triggers additional reverse remodeling in patients with idiopathic non-ischemic cardiomyopathy. Int Heart J 2016; 57: 717-24.

22. Kainuma S, Taniguchi K, Toda K, et al. B-type natriuretic peptide response and reverse left ventricular remodeling after surgical correction of functional mitral regurgitation in patients with advanced cardiomyopathy. J Cardiol 2015; 66: 279-85. 
23. Okamoto H, Hori M, Matsuzaki M, et al. Minimal dose for effective clinical outcome and predictive factors for responsiveness to carvedilol: Japanese chronic heart failure (J-CHF) study. Int J Cardiol 2013; 164: 238-44.
24. Masson S, Latini R, Anand IS, et al. Prognostic value of changes in N-terminal pro-brain natriuretic peptide in Val-HeFT (Valsartan Heart Failure Trial). J Am Coll Cardiol 2008; 52: 997-1003. 